\title{
Rapid Surface Functionalization of Hydrogen-Terminated Silicon by Alkyl Silanols
}

\author{
Jorge Escorihuela ${ }^{\dagger}$ and Han Zuilhof*, ${ }^{*},+, \S_{(0)}$ \\ ${ }^{\dagger}$ Laboratory of Organic Chemistry, Wageningen University and Research, Stippeneng 4, 6708 WE Wageningen, The Netherlands \\ ${ }^{\ddagger}$ School of Pharmaceutical Sciences and Technology, Tianjin University, Tianjin 300072, China \\ ${ }^{\S}$ Department of Chemical and Materials Engineering, King Abdulaziz University, Jeddah 23218, Saudi Arabia
}

\section{Supporting Information}

ABSTRACT: Surface functionalization of inorganic semiconductor substrates, particularly silicon, has focused attention toward many technologically important applications, involving photovoltaic energy, biosensing and catalysis. For such modification processes, oxide-free (H-terminated) silicon surfaces are highly required, and different chemical approaches have been described in the past decades. However, their reactivity is often poor, requiring long reaction times $(2-18 \mathrm{~h})$ or the use of UV light $(10-30 \mathrm{~min})$. Here, we report a simple and rapid surface functionalization for H-terminated $\mathrm{Si}(111)$ surfaces using alkyl silanols. This catalyst-free surface reaction is fast (15 $\mathrm{min}$ at room temperature) and can be accelerated with UV light irradiation, reducing the reaction time to $1-2 \mathrm{~min}$. This grafting procedure leads to densely packed organic monolayers that are hydrolytically stable (even up to 30 days at pH 3 or 11) and can display excellent antifouling behavior against a range of organic polymers.

\section{INTRODUCTION}

Surface modification of inorganic substrates is an extensive research area as it has a wide range of applications in the fields of biotechnology, biosensing, micro- and nanotechnology. ${ }^{1-3}$ Among all substrates, silicon surfaces are of utmost interest because of its unique optoelectronic properties, ${ }^{4-6}$ which provide applications in biosensing, ${ }^{7,8}$ molecular electronics ${ }^{9,10}$ and solar cell devices. ${ }^{11-13}$ In this regard, the nature of the grafting to the silicon surface is a critical issue for electronic applications, as the chemical identity of this linkage can have significant effects on the electronics of the underlying semiconductor. ${ }^{14-17}$ Molecular control over such siliconbased surface modification can be achieved by the attachment of self-assembled monolayers (SAMs), ${ }^{18-20}$ possibly followed by surface-initiated polymerizations or well-defined molecular layer deposition. ${ }^{21}$ The attachment of SAMs thus provides a simple and elegant approach, as it allows an easy tuning of the properties as well as a desired follow-up reactivity or functionality. ${ }^{22}$

Surface modification with alkyl silanes is one of the most commonly used methods to prepare monolayers on silicon oxide $(\mathrm{SiOx})$ surfaces, as it allows the rapid formation of a covalent bond with the surface and as easy chemical modifications. ${ }^{23-25}$ Despite these advantages, this method often suffers from the low surface $\mathrm{OH}$ group content of the Si surface oxide ${ }^{26}$ and uniform monolayers are difficult to obtain using solution-phase deposition methods, as undesirable polysiloxane networks are often formed. ${ }^{27,28}$ Recently, surface modification of $\mathrm{SiOx}$ surfaces based on the grafting of hydrosilanes using tris(pentafluorophenyl)borane $\left(\mathrm{B}\left(\mathrm{C}_{6} \mathrm{~F}_{5}\right)_{3}\right)$ as catalyst has gained interest, specifically due to its short reaction times (5-10 $\mathrm{min}$ for full surface coverage). ${ }^{29-31}$ However, modification routes for the attachment of organic species on a Si substrate without intervening oxide are for many applications strongly preferred, as they significantly reduce the density of defect states and traps on $\mathrm{Si} / \mathrm{Ge}$ surfaces. ${ }^{32}$ In this regard, a variety of surface modification methods has been investigated with the aim of preserving the near-ideal electrical and electronic properties of $\mathrm{H}$-terminated $\mathrm{Si}$ surfaces, while providing a handle for further functionality. ${ }^{11,18,33}$ Typical modification strategies based on sonochemistry, ${ }^{34}$ thermal activation, ${ }^{35,36}$ use of catalysts or Lewis acids, ${ }^{37}$ or visible light irradiation, ${ }^{38}$ have been widely studied, but often require long reaction times $(2-18 \mathrm{~h})$. Alternative, more rapid (10-30 min) grafting approaches based on the use of UV light (254 $\mathrm{nm}$ ) have been reported, ${ }^{39-41}$ but these, of course, limit other substituents in the molecule to those that are not photoreactive at this short wavelength. Based on these approaches, we thus figured that the reverse of the reaction of alkyl hydrosilanes with $\mathrm{SiOx}$ surfaces, namely that of alkyl silanols with oxide-free $\mathrm{H}$-terminated $\mathrm{Si}$ would constitute an attractive surface functionalization.

Herein, we report a fast and efficient surface modification for atomically flat, $\mathrm{H}$-terminated $\mathrm{Si}(111)$ [further: $\mathrm{H}-\mathrm{Si}$ ] with readily accessible silanol molecules, containing one, two or

Received: February 1, 2017

Published: April 14, 2017 
three hydroxyl groups (Scheme 1). In addition, highly fluorinated monolayers were prepared and their antifouling

Scheme 1. Functionalization of $\operatorname{Si}(111)$ Surfaces: (a) Chemical Etching of $\mathrm{Si}(111)$ In $40 \%$ Aqueous $\mathrm{NH}_{4} \mathrm{~F}$ Solution and (b) Grafting of Silanol Derivatives
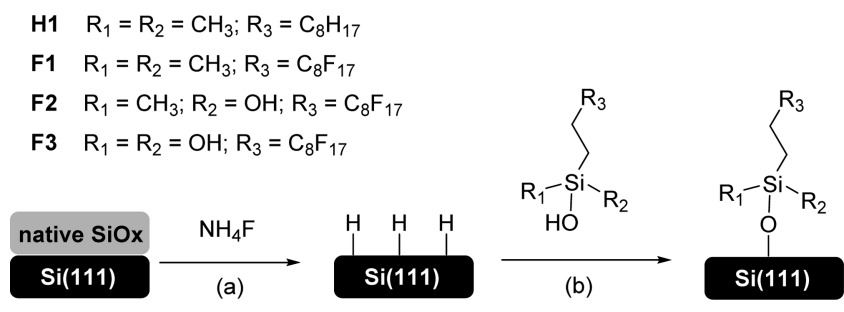

behavior toward organic polymers studied, as part of an ongoing program to delineate the factors that govern the barely studied field of fouling by organic polymers. The present modification procedure provides as a first advantage over other $\mathrm{Si}$ modification routes that the reaction kinetics (thermal reaction: $15 \mathrm{~min}$ at room temperature; UV reaction: $1-2 \mathrm{~min}$ ) are one to several orders of magnitude faster compared to other attachment chemistries onto $\mathrm{H}-\mathrm{Si}$. In addition, it is simple and effective.

\section{RESULTS AND DISCUSSION}

Monolayer Formation. As proof-of-principle, a silanol derivative containing an alkyl chain, decyldimethylsilanol (H1), was synthesized from the corresponding chlorosilane, analogous to reported procedures (see Supporting Information). ${ }^{42}$ Next, the grafting of compound $\mathbf{H 1}$ onto an atomically flat, hydrogen-terminated $\mathrm{Si}(111)$ was studied. For that, $\mathrm{Si}(111)$ samples were cleaned and etched according to reported procedures, $^{30}$ via acetone sonication, piranha cleaning $\left(\mathrm{H}_{2} \mathrm{SO}_{4} / \mathrm{H}_{2} \mathrm{O}_{2}\right.$ 3:1) and argon-saturated $\mathrm{NH}_{4} \mathrm{~F}$ (40\% aqueous solution) etching. Once $\mathrm{H}$-terminated surfaces were prepared, they were immediately immersed in $2 \mathrm{~mL}$ of dry $\mathrm{CH}_{2} \mathrm{Cl}_{2}$ containing $\mathrm{H} 1$ and $1 \mathrm{~mol} \%$ of $\mathrm{B}\left(\mathrm{C}_{6} \mathrm{~F}_{5}\right)_{3}$, analogous to the procedure for modification of $\mathrm{SiOx}$ surfaces by hydrosilanes. ${ }^{29}$ As a control experiment, the same reaction was performed in the absence of catalyst. After the reaction, the modified surfaces were rinsed and sonicated with $\mathrm{CH}_{2} \mathrm{Cl}_{2}$ to remove any physisorbed silanols. When the reaction was carried out in the presence of $1 \mathrm{~mol} \%$ of catalyst at room temperature, XPS revealed that the $\mathrm{C} / \mathrm{Si}$ content remained unchanged after $1 \mathrm{~h}$ or even $24 \mathrm{~h}$ reaction time (entries 1 and 2 ) or upon increasing the catalyst loading up to $5 \mathrm{~mol} \%$ (entry 3 ). However, in the absence of the aforementioned catalyst, XPS analysis revealed that the $\mathrm{C} / \mathrm{Si}$ content increased notably (entry 4 ) relative to the unmodified substrate, indicating the effective grafting of the silanol $\mathbf{H 1}$ after $1 \mathrm{~h}$.

Such grafting was also corroborated by the increase in the static water contact angle (SCA) from $80^{\circ}$ (for H-terminated $\mathrm{Si}(111)$ ) to a value of $105^{\circ}$, and formation of an organic monolayer with a thickness of $\sim 0.9 \mathrm{~nm}$ as measured by ellipsometry and XPS (according to the $\mathrm{C} / \mathrm{Si}$ ratio; see Supporting Information). The reaction time could be reduced down to $30 \mathrm{~min}$ and similar $\mathrm{C} / \mathrm{Si}$ ratios were still obtained (entry 5). Finally, it is worth mentioning that the reaction also occurred in the absence of solvent (entry 6). No changes in the XPS spectra of modified surfaces were observed upon rinsing and sonication with $\mathrm{CH}_{2} \mathrm{Cl}_{2}$, suggesting the formation of covalently bound monolayers.

While the Lewis acid $\mathrm{B}\left(\mathrm{C}_{6} \mathrm{~F}_{5}\right)_{3}$ is an excellent catalyst ${ }^{43}$ in the grafting of hydrosilane compounds onto oxidized silicon surfaces, ${ }^{29-31}$ these results show it to be ineffective for the inverse reaction on $\mathrm{H}-\mathrm{Si}$ surfaces. On the basis of the observed results, we hypothesize that this organoborane catalyst ${ }^{44-48}$ may actually passivate the $\mathrm{H}$-terminated silicon surface and thus dramatically slows down the attachment of silanol compounds. This $\mathrm{B}\left(\mathrm{C}_{6} \mathrm{~F}_{5}\right)_{3}$ catalyst was also shown to be ineffective on $\mathrm{H}-$ $\mathrm{Si}$ nanocrystals ${ }^{49}$ and or $\mathrm{H}$-terminated porous $\mathrm{Si}^{50}$

Next, given their relative ease for characterization by SCA and XPS measurements, and our wider research goal to rapidly form fluorinated monolayers onto $\mathrm{Si}^{51}{ }^{51}$ three silanol derivatives containing a fluorinated alkyl chain $\left(-\mathrm{C}_{8} \mathrm{~F}_{17}\right)$ were synthesized from the corresponding chlorosilanes in high yields (see Supporting Information), and used to modify $\mathrm{H}-\mathrm{Si}$ surfaces. These fluorinated silanol derivatives have one (monodentate, F1), two (bidentate, F2) or three (tridentate, F3) hydroxyl groups that can interact with the surface. ${ }^{52}$ The degree of modification was evaluated by measuring the SCA of the functionalized surfaces (Figure 1, Table 1). For silanol F1, the

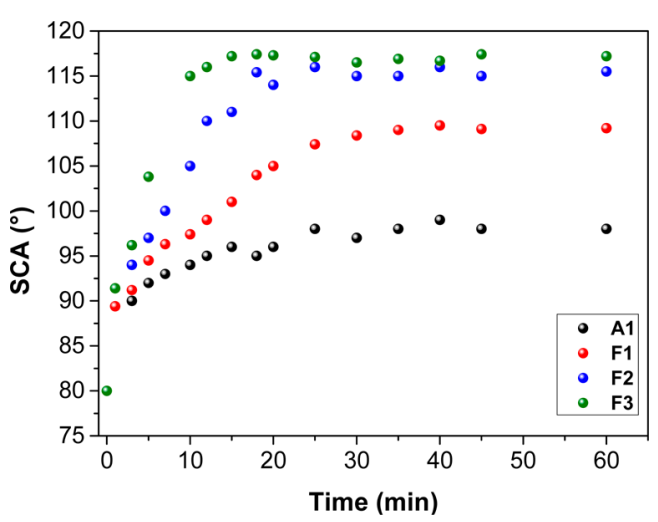

Figure 1. SCA of silanol H1, F1, F2 and F3 monolayers vs reaction time. Each data point represents the average of five separately prepared monolayers the relative error is less than $\pm 2^{\circ}$.

Table 1. Optimization of Reaction Conditions for the Attachment of Silanol H1 onto Hydrogen-Terminated Si(111) Surfaces

\begin{tabular}{clccc} 
entry & solvent & cat. (mol \%) & time (h) & C/Si ratio (\%) \\
1 & $\mathrm{CH}_{2} \mathrm{Cl}_{2}$ & 1 & 1 & 0.06 \\
2 & $\mathrm{CH}_{2} \mathrm{Cl}_{2}$ & 5 & 24 & 0.07 \\
3 & $\mathrm{CH}_{2} \mathrm{Cl}_{2}$ & 5 & 1 & 0.07 \\
4 & $\mathrm{CH}_{2} \mathrm{Cl}_{2}$ & 0 & 1 & 0.30 \\
5 & $\mathrm{CH}_{2} \mathrm{Cl}_{2}$ & 0 & 0.5 & 0.32 \\
6 & none & 0 & 0.5 & 0.31 \\
\hline
\end{tabular}

SCA gradually increased from $80^{\circ}$ to a value of $109^{\circ}$ after 30 min, whereas for F2 and F3, more hydrophobic surfaces $\left(112^{\circ}\right.$ for $\mathbf{F} 2$ and $118^{\circ}$ for $\mathbf{F} 3$ ) were obtained in even shorter reaction times $(15 \mathrm{~min})$, in which the SCA became similar to that of analogous alkyne-derived fluorinated SAMs on $\mathrm{Si}(111) .^{53}$ These results also show the higher reactivity of bidentate and tridentate silanol derivatives over the homologous monodentate. The grafting was also confirmed by infrared reflection absorption spectrometry (IRRAS). After reaction with silanol derivatives, $\mathrm{C}-\mathrm{H}$ stretching bands appeared below $3000 \mathrm{~cm}^{-1}$, 
accompanied by a diminished intensity of the $\mathrm{Si}-\mathrm{H}$ vibrational bands, indicating the reaction and subsequent consumption of this moiety on the surface. For F2 and F3, eventually all hydroxyl groups were bound to the $\mathrm{Si}(111)$ substrate as no evidence of unreacted hydroxyls moieties was observed, indicated by the lack of an IR peak around $3100 \mathrm{~cm}^{-1}$.

This difference in reactivity was also confirmed by ellipsometry (Figure S19, Supporting Information). The ellipsometric thickness of the monolayers investigated in this study was after $30 \mathrm{~min}$ reaction time found to be $0.9-1.1$ $( \pm 0.2) \mathrm{nm}$, which is similar to the theoretically expected thickness calculated for a close-packed monolayer with fully extended molecules and a near-perpendicular orientation to the surface. This result also suggests that no undesirable reaction with neighboring hydroxyls to form laterally cross-linked layers (in analogy to silanes) was observed for F2 and F3 compounds. However, this is not the case when longer reaction times were investigated, as multilayers for bidentate and tridentate silanol derivatives, were observed after $2 \mathrm{~h}$. These undesirable multilayers for F2 and F3 compounds yielded highly hydrophobic surfaces $\left(\mathrm{SCA} \sim 124^{\circ}\right)$ and thicknesses around 3-4 nm, as calculated from the $\mathrm{C} / \mathrm{Si}$ ratio determined by XPS. The silanol-derived monolayers showed sharp signals for the antisymmetric and symmetric $\mathrm{C}-\mathrm{H}$ stretching vibrations at 2921 and $2851 \mathrm{~cm}^{-1}$, respectively, which is indicative of the formation of a well-defined monolayer (Figures S27-S30, Supporting Information), especially given the Si-bound methyl groups. $^{54,55}$

The topography of the modified Si surfaces was studied after completion of the reaction (as indicated by SCA) by atomic force microscopy (AFM), and yielded a surface roughness of $<0.3 \mathrm{~nm}$ for all surfaces, i.e., identical to the atomically flat $\mathrm{H}$ terminated surface obtained after etching (Figures S21-S26, Supporting Information). No evidence of islands or granules was observed in the AFM images, in accordance with the presence of a fully formed monolayer on the surface.

Interestingly, the attachment of F1 was extremely fast under UV light $(254 \mathrm{~nm})$ irradiation. As shown in Figure 2, a SCA of $111^{\circ}$ was already reached within $1 \mathrm{~min}$ of UV light irradiation, and prolonged irradiation (up to $5 \mathrm{~min}$ ) did not change this situation appreciably. Analogous experiments with bi- and tridentate compounds also showed that the grafting reaction rate was higher under UV light irradiation (1 min), and SCA of 112 and $118^{\circ}$ were obtained for F2 and F3, respectively. However, irradiation times longer than $10 \mathrm{~min}$ yielded the increase of layer thickness, suggesting multilayer formation. These data indicate that the UV-induced attachment of silanols is by far the fastest modification of oxide-free $\mathrm{Si}$ surface reported up to now.

The use of light-based surface modification approaches is highly attractive as it allows surface patterning by exposure through a mask. ${ }^{56}$ In this regard, a proof-of-concept photomasking experiment was carried out using a $254 \mathrm{~nm}$ lamp (3 $\mathrm{min})$ as depicted in Figure 2A, yielding hydrophobic F1functionalized surfaces on the irradiated areas and hydrophilic nonfunctionalized surfaces on the covered areas. SCA $\left(110^{\circ}\right.$ and $\sim 45^{\circ}$, respectively) and XPS F 1 s and C 1 s narrow scans (Figure 2C and 2D) confirm this. To demonstrate the ability to locally functionalize the surface, photolithography was performed using a contact mask (gold electron microscope grid) to pattern the surface with silanol F1. An image obtained using a scanning electron microscopy (SEM) showed the pattern from the mask was effectively transferred to the surface

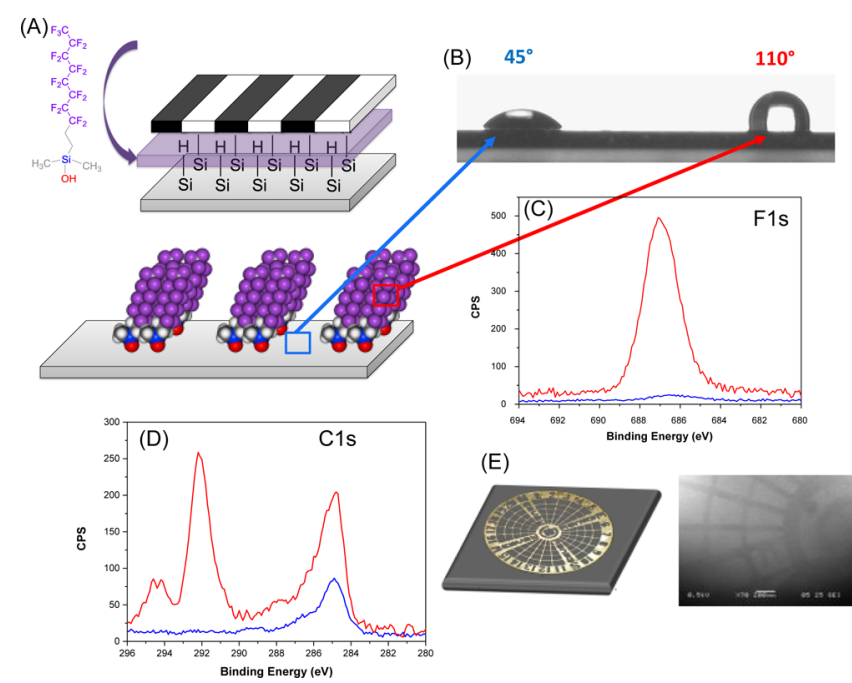

Figure 2. (A) Schematic representation of a photomasking experiment, (B) SCA of F1-functionalized $\left(110^{\circ}\right)$ and nonfunctionalized $\left(45^{\circ}\right) \mathrm{H}$-terminated $\mathrm{Si}$, (C) F 1s XPS narrow scan of F1-functionalized (red) and nonfunctionalized (blue) H-terminated Si, (D) C 1s XPS narrow scan of F1-functionalized (red) and nonfunctionalized (blue) $\mathrm{H}$-terminated $\mathrm{Si}$ and (E) scanning electron microscopy (SEM) image obtained using a gold photomask.

(Figure 2E). The light-induced attachment also works at longer wavelengths (365 and $447 \mathrm{~nm}$; filters used to block residual $<300 \mathrm{~nm}$ wavelengths) - with these wavelengths the reaction takes ca. 8 and $15 \mathrm{~min}$ to complete; this is significantly longer than at $254 \mathrm{~nm}$, but again much faster than required for the attachment of, e.g., alkenes or alkynes at $365 \mathrm{~nm}$ or longer wavelengths. 57,58

The successful formation of monolayers was corroborated by XPS. Table 2 shows the elemental concentration (in atom \%)

Table 2. Atomic Percentages (Average Value of Five Separately Prepared Monolayers) for the Elements Present in the Different Photochemically $(254 \mathrm{~nm}, 2 \mathrm{~min})$ Modified Si(111) Surfaces

\begin{tabular}{clcccc} 
entry & modification & Si 2p (\%) & O 1s (\%) & C 1s (\%) & F 1s (\%) \\
1 & Acetone cleaning & 58.8 & 30.3 & 10.9 & - \\
2 & Piranha cleaning & 68.6 & 29.6 & 1.8 & - \\
3 & NH$_{4}$ F etching & 95.2 & 2.2 & 2.1 & - \\
4 & H1 & 72.3 & 4.6 & 22.8 & - \\
5 & F1 & 54.6 & 5.1 & 17.1 & 23.2 \\
6 & F2 & 51.5 & 4.2 & 17.0 & 27.3 \\
7 & F3 & 52.5 & 5.3 & 15.8 & 26.4 \\
\hline
\end{tabular}

derived from XPS measurements after each step of the surface modification. As shown, the \% $\mathrm{C}$ and $\% \mathrm{O}$ decreased significantly after piranha cleaning and $\mathrm{NF}_{4} \mathrm{H}$ etching, respectively. After reaction with the silanol compounds, a clear increase in the \% C for $\mathbf{H 1}$ (entry 4), and \% C and \% F for F1, F2 and F3 (entries 5-7) was observed, confirming the grafting. The XPS F/C atomic ratio calculated as an average of three different fluorinated-modified surfaces was $1.41 \pm 0.05$ for F1, $1.60 \pm 0.08$ for F2 and $1.67 \pm 0.07$ for F3, in excellent agreement with the theoretical values of $1.42,1.54$ and 1.70, respectively. A detailed study from the $\mathrm{Si} 2 \mathrm{p}$ core level spectra revealed no contribution in the $102-104 \mathrm{eV}$ range from oxide 
species, ${ }^{59}$ supporting the continued presence of an oxide-free $\mathrm{Si}(111)$ surface.

A detailed investigation of the XPS C 1s spectra confirmed the successful monolayer formation, as shown by peak deconvolution into different components corresponding to the carbon atoms having different environments. For compound $\mathrm{HI}$, the $\mathrm{C}$ 1s spectrum was deconvoluted into two main peaks (Figure 3A): the alkyl peak at $285.0 \mathrm{eV}$, and a
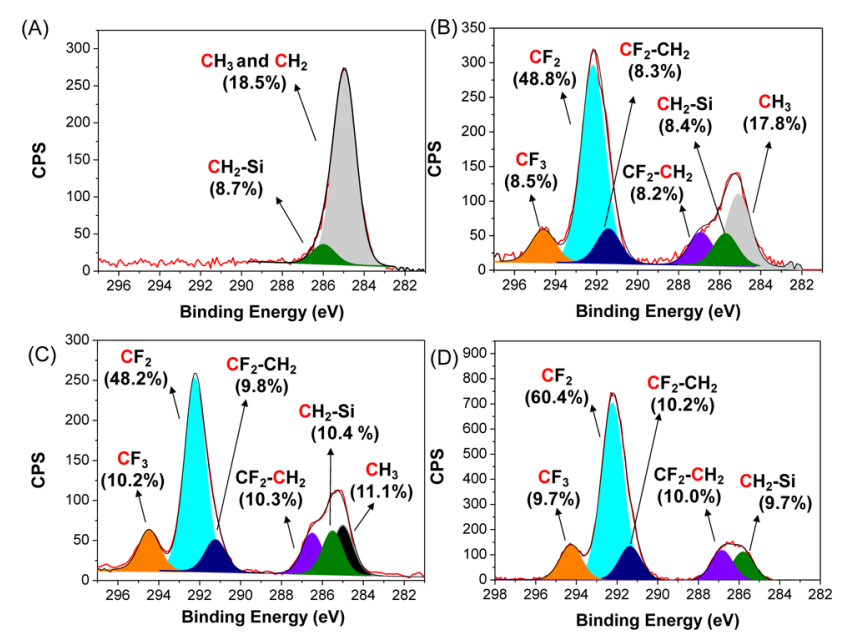

Figure 3. XPS $\mathrm{C}$ 1s spectra of monolayers on $\mathrm{H}-\mathrm{Si}$ (111) derived from silanol H1 (A) and perfluorinated compounds F1 (B), F2 (C) and F3 (D).

peak assigned to $-\underline{\mathrm{CH}_{2}}-\mathrm{Si}$ at $286.0 \mathrm{eV}$. For compounds $\mathrm{F} \mathbf{1}-$ F3 (Figure $3 \mathrm{~B}-\mathrm{D}$ ), the $\mathrm{C} 1 \mathrm{~s}$ spectra were deconvoluted into the alkyl peak at $285.0 \mathrm{eV}$ (for F1 and F2), and peaks for $-\underline{\mathrm{CH}}_{2}-\mathrm{Si},-\mathrm{CF}_{2}-\underline{\mathrm{CH}}_{2}-,-\underline{\mathrm{CF}}_{2}-\mathrm{CH}_{2}-,-\underline{\mathrm{CF}}_{2}-$ and $-\underline{\mathrm{CF}}_{3}$ at 285.8, 286.7, 291.3, 292.0, and $294.4 \mathrm{eV}$, respectively. DFTderived simulated C 1s XPS spectra ${ }^{60}$ agreed well with the experimental spectra (Figure S36, Supporting Information), and all wide and $\mathrm{C} 1 \mathrm{~s}$ narrow scans showed peak intensities in line with the monolayer structure.

Considerations Regarding Reaction Mechanism. In order to probe the mechanism of this reaction, the attachment of monodentate silanol F1 onto the H-terminated $\mathrm{Si}(111)$ surface was investigated under different conditions, and the degree of modification was evaluated by measuring the SCA and XPS of the functionalized surfaces. As relative benchmarks we used the situation in the presence of $1 \%$ of $\mathrm{B}\left(\mathrm{C}_{6} \mathrm{~F}_{5}\right)_{3}$ (no reaction), and the room-temperature reaction in the absence of the organoborane compound (SCA of $109^{\circ}$ after 20-30 min). When the room temperature reaction was performed without catalyst and in full darkness, then a decrease in the grafting rate was clearly visible, as indicated by SCA measurements and XPS (F/C ratio). Upon addition of a radical initiator ( $1 \mathrm{~mol} \%$ of 4 bromobenzenediazonium tetra-fluoroborate, BBD) - which been proved to be an effective catalyst for the grafting of organosulphur and organodiselenide compounds on $\mathrm{H}$ terminated porous $\mathrm{Si}$ surfaces ${ }^{61}$ - the immobilization proceeded slightly faster, as SCA around $109^{\circ}$ were obtained after $20 \mathrm{~min}$. The successful grafting was also confirmed by $\mathrm{XPS}$, as a $\mathrm{F} / \mathrm{C}$ atomic ratio of around 1.41 was obtained, in agreement with the theoretical value of 1.42 . In contrast, in the presence of a radical trap ( $1 \mathrm{~mol} \%$ of (2,2,6,6-tetramethylpiperidin-1-yl)oxyl), TEMPO), ${ }^{62}$ the grafting was observed to be significantly slower and more than $60 \mathrm{~min}$ were needed to reach a SCA of $109^{\circ}$. These results support the involvement of a radical mechanism in the grafting reaction. The effect of the temperature on the attachment reaction was studied at 50 and $80{ }^{\circ} \mathrm{C}$, and both SCA and XPS (C/Si atomic ratio) indicated that that the grafting reaction was $2-3$ times faster as temperature increased.

A possible mechanism of this grafting procedure may proceed through a nucleophilic attack onto the $\mathrm{Si}-\mathrm{H}$ surface by an $\mathrm{O}$ lone pair from the silanol compound, analogous to what has been observed for alcohols on $\mathrm{Si}-\mathrm{H}$ surfaces, ${ }^{63}$ followed by the loss of the two hydrogen atoms to give an oxidative addition ( $\mathrm{Si}-\mathrm{O}-\mathrm{Si}$ bond formation) on the $\mathrm{H}$ terminated surface. Alternatively, given the observed dependence on radical initiators and radical scavengers, the reaction might take place on surface-bound Si radicals, with loss of $\mathrm{H}_{2}$ from the radical intermediate yielding another surface-bound $\mathrm{Si}$ radical. $\mathrm{M} 11 / 6-311+\mathrm{G}(\mathrm{d}, \mathrm{p})$ density functional theory calculations $^{64}$ of the overall reaction enthalpy were used to further probe the significant difference in reactivity for the $\mathrm{R}-$ $\left(\mathrm{CH}_{3}\right)_{2} \mathrm{SiOH}, \mathrm{R}-\left(\mathrm{CH}_{3}\right) \mathrm{Si}(\mathrm{OH})_{2}$ and $\mathrm{R}-\mathrm{Si}(\mathrm{OH})_{3}$ reagents (see Supporting Information). For that, we assumed that the $\mathrm{H}$ terminated surface and the silanol reagent will react forming the immobilized product and $\mathrm{H}_{2}$. The $\mathrm{H}-\mathrm{Si}(111)$ substrate was mimicked using tris(trihydrosilyl)silane as a model surface, which resembles the top layer of the $\mathrm{H}-\mathrm{Si}(111)$ surface. These calculations clearly show that $\mathbf{F} 3$ has the most favorable reaction energy for monolayer formation $(-59.4 \mathrm{kcal} / \mathrm{mol})$; with $\mathbf{F} 2$ yielding $1.6 \mathrm{kcal} / \mathrm{mol}$ less per $\mathrm{Si}-\mathrm{O}-\mathrm{Si}$ linkage and $\mathbf{F 1}$ even $13.0 \mathrm{kcal} / \mathrm{mol}$ less. For the light-induced reaction we do, in fact, not notice much of a dependence on the number of $-\mathrm{OH}$ groups. If one would presume the surface to be partially positively charged due to the optical excitation, ${ }^{58}$ then the most extreme case would be a representation by a radical cation. We thus repeated the above calculation with tris(trihydrosilyl) silane radical cation as a surface model, to find the corresponding binding energies to be $9.4,8.7$, and $9.0 \mathrm{kcal} /$ mol, for covalent attachment via one $\mathrm{Si}-\mathrm{O}$ bond of $\mathrm{F} 1, \mathrm{~F} 2$ and F3, respectively. In other words: these are all more or less the same, in line with the absence of any reactivity difference in the photochemical reaction.

Monolayer Stability. The stability of the monolayer is a crucial parameter, as the performance and durability of biosensing and electronic devices depends on it to a large degree. $^{65^{\circ}}$ To study the hydrolytic stability, silanol-derived monolayers were immersed up to 30 days in four different aqueous media containing deionized water, PBS ( $\mathrm{pH} 7.4)$, an acidic $(\mathrm{HCl})$ solution at $\mathrm{pH} 3$, and a basic $(\mathrm{NaOH})$ solution at $\mathrm{pH} 11$, all under continuous stirring. ${ }^{66}$ After $1,3,5,7$, and 30 days, samples were cleaned and sonicated in water. The hydrolytic stability was followed by SCA measurements and carbon desorption rates, using the $\mathrm{C} / \mathrm{Si}$ ratio from XPS survey scans; in each case data were normalized to the height at the starting surface. In general, no significant changes were detected in the SCA (Figure 4) and $\mathrm{C} / \mathrm{Si}$ ratio (Figures S35-S38, Supporting Information) after immersion for 1 and 3 days in any of the solutions. The $\mathbf{H} \mathbf{1}$ and $\mathbf{F} \mathbf{1}$ monolayers showed after 30 days of immersion in basic media a reduction of the $\mathrm{C} / \mathrm{Si}$ ratio up to $\sim 30 \%$, implying removal of a significant fraction of the monolayer although the surface remained hydrophobic as indicated by SCA around $90^{\circ}$ (for H1) and $95^{\circ}$ (for F1). While this result is already quite reasonable, the F2 (Figure 4C) and F3 (Figure 4D) monolayers perform even better: After prolonged immersion for 30 days in $\mathrm{H}_{2} \mathrm{O}$ no significant 

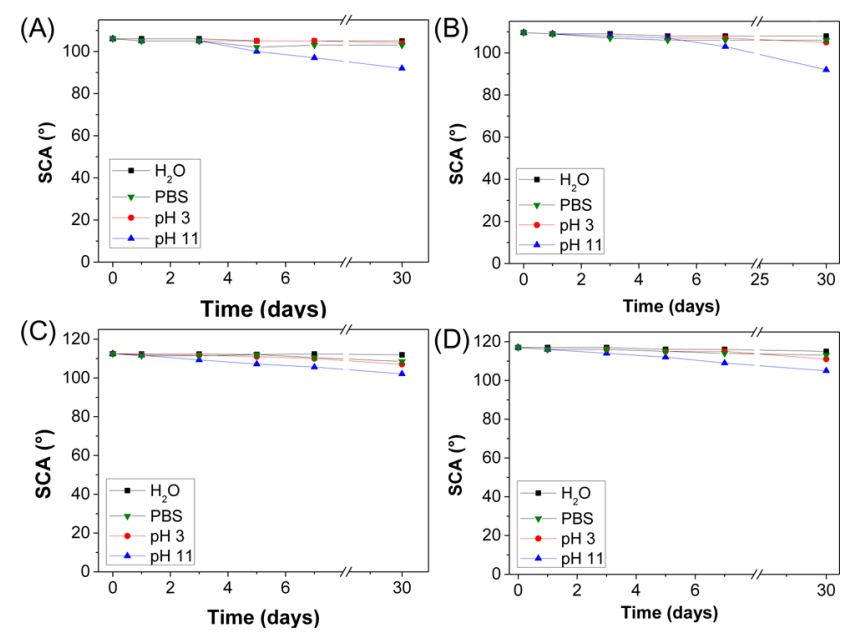

Figure 4. Hydrolytic stability of $\mathrm{Si}(111)$ surfaces modified with $\mathrm{H1}$ (A) and perfluorinated compounds F1 (B), F2 (C) and F3 (D) as followed by SCA (lines connecting data points are a mere guide to the eye). Each data point is the average from five separately prepared monolayers.

reduction was detected in SCA or $\mathrm{C} / \mathrm{Si}$ ratio by XPS; in PBS and $\mathrm{pH} \mathrm{3}$, the SCA decreased only a few degrees, and $\mathrm{C} / \mathrm{Si}$ ratio by just $3-7 \%$. At $\mathrm{pH} 3$, SCA values for F2 and F3 only decreased by $\sim 5^{\circ}$, and the $\mathrm{C} / \mathrm{Si}$ ratio by $6 \%$, while even upon 30 days in $\mathrm{pH} 11$, only a $15 \%$ decrease of the $\mathrm{C} / \mathrm{Si}$ ratio was observed for the F3-derived monolayer, with the SCA still $>105^{\circ}$. This indicates the formation of highly stable monolayers derived from F2 and F3, which we relate to the mode of attachment, in which, e.g., the F3 compound not only reacts the fastest, but also yields up to three $\mathrm{Si}-\mathrm{O}-\mathrm{Si}$ bonds with concomitantly high stabilities.

Antifouling Properties. Finally, these monolayers were studied with respect to their antifouling characteristics toward organic polymers, as part of our wider ranging studies in this area. ${ }^{67}$ Fouling is generally defined as the deposition or accumulation of unwanted materials on a solid surface, causing severe damage of equipment, ${ }^{68}$ and is particularly relevant for reduced flow, such as in orifices in next-generation Si-based printer heads and SiN-based microsieves (typically pore size: $400-4000 \mathrm{~nm}$ ). Both monolayers ${ }^{51}$ and polymer brushes ${ }^{69}$ have been used to minimize such organic polymer fouling, but all previously made coatings took many hours and (for the brushes) multistep surface-bound conversions. Therefore, the antifouling properties of the prepared monolayers were studied toward a selection of commonly used polymers with similar molecular weight $\left(M_{\mathrm{n}} \sim 5000 \mathrm{~g} / \mathrm{mol}\right)$, namely poly(ethylene glycol) (PEG), poly(acrylic acid) (PAA), poly(vinyl acetate) (PVA), polystyrene (PS), poly(2-vinylpyridine) (P2VP) and poly $(N$-isopropylacrylamide (PNIPAM). Polymer adsorption was investigated by means of XPS and ellipsometry on functionalized samples. After immersion of unmodified silicon in the polymer solution ( $10 \mathrm{mg} / \mathrm{mL}$ in DMF) during $18 \mathrm{~h}$ and a standardized washing protocol, ${ }^{47}$ XPS analysis showed a notable increase of $\mathrm{C}$ content. From ellipsometric measurements, a fouling layer of 1.6-4.6 nm was found for the different polymers under study (Figure 5), confirming that such polymer really foul an unmodified $\mathrm{Si}$ surface. In contrast, for the alkyland especially the fluoroalkyl-modified surfaces, this fouling was significantly reduced, with thickness increases lower than 0.4 $\mathrm{nm}$. The antifouling behavior of the $\mathrm{F}_{17}$ monolayers such as F2

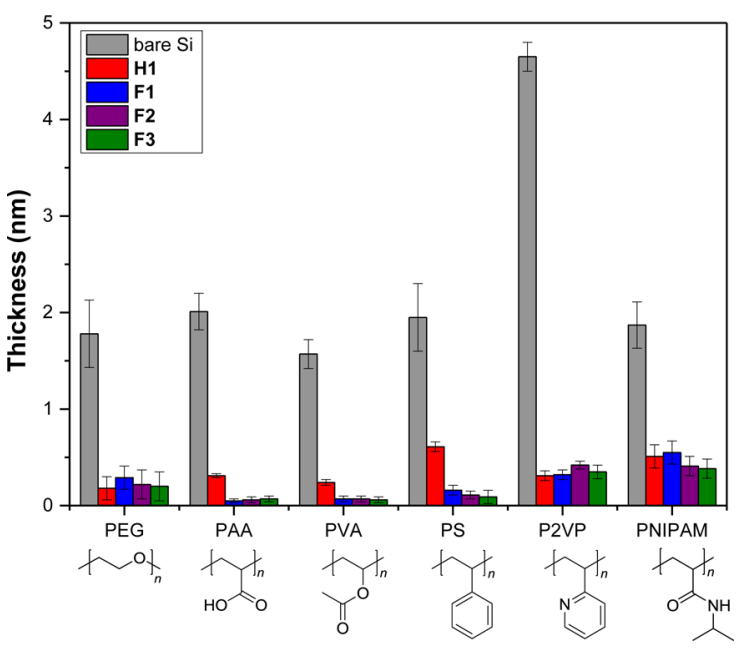

Figure 5. Ellipsometric thickness increase of different monolayers after immersing the monolayer into a polymer solution $(10 \mathrm{mg} / \mathrm{mL}$ in DMF) for $18 \mathrm{~h}$.

and especially F3 is thereby near identical to that of previously studied perfluorinated alkyne-derived monolayers, ${ }^{51}$ which require much longer reaction times to be formed.

\section{CONCLUSIONS}

We have established a fast and catalyst-free grafting method for the attachment of silanol compounds onto oxide-free, $\mathrm{H}$ terminated $\mathrm{Si}(111)$ surfaces that is $2-3$ orders of magnitude faster than competing attachment chemistries. This approach yields hydrophobic monolayers that display a high hydrolytic stability under physiological conditions (PBS buffer), and under both acidic and basic media ( $\mathrm{pH} 3$ and 11). When highly fluorinated monolayers are formed, these display very good antifouling properties toward a wide series of polymers. We expect this attachment chemistry can be easily extended to a range of other functionalities, giving it substantial potential in the scalable functionalization of silicon-based devices. Further mechanistic investigations are currently ongoing in our laboratories.

\section{EXPERIMENTAL SECTION}

Chemicals. N-type phosphorus-doped silicon (111) wafers, with resistivity of $0.01-0.018 \Omega \cdot \mathrm{cm}$, were used in these experiments. Heptadecafluoro-1,1,2,2-tetrahydrodecyl) dimethylchlorosilane (95\% purum), (heptadecafluoro-1,1,2,2-tetrahydrodecyl)methyldichlorosilane (97\% purum) and $1 \mathrm{H}, 1 \mathrm{H}, 2 \mathrm{H}, 2 \mathrm{H}$-perfluorodecyltrichlorosilane (97\% purum, stabilized with copper) were purchased from abcr $\mathrm{GmbH}$. Chloro-decyl-dimethylsilane, acetone, diethyl ether, $\mathrm{CH}_{2} \mathrm{Cl}_{2}$ and triethylamine $\left(\mathrm{Et}_{3} \mathrm{~N}\right)$ were purchased from Sigma-Aldrich. For surface modification, $\mathrm{CH}_{2} \mathrm{Cl}_{2}$ was dried in a PureSolv EN solvent purification system (Innovative Technology). Deionized (DI) water was obtained from a Milli-Q Integral water purification system (Merck-Millipore). Phosphate buffered saline (PBS, $10 \mathrm{mM}, \mathrm{pH}$ 7.4) was prepared from a solution of $\mathrm{NaCl}(8.01 \mathrm{~g} / \mathrm{L}), \mathrm{Na}_{2} \mathrm{HPO}_{4}(1.41 \mathrm{~g} /$ $\mathrm{L}), \mathrm{KH}_{2} \mathrm{PO}_{4}(0.27 \mathrm{~g} / \mathrm{L})$ and $\mathrm{KCl}(0.20 \mathrm{~g} / \mathrm{L})$ in $\mathrm{DI}$ water.

Monolayer Preparation. A piece of $\mathrm{Si}$ (111) wafer was first rinsed several times with acetone, followed by sonication for $15 \mathrm{~min}$ in acetone. The $\mathrm{Si}$ wafer was then oxidized in freshly prepared piranha solution $\left(\mathrm{H}_{2} \mathrm{SO}_{4} / \mathrm{H}_{2} \mathrm{O}_{2} 3: 1\right)$ for $30 \mathrm{~min}$ at $60{ }^{\circ} \mathrm{C}$. After piranha treatment, the substrates were immersed immediately in water and rinsed thoroughly, followed by drying with a stream of argon. Subsequently, the $\mathrm{Si}$ (111) substrates were etched in an argonsaturated $40 \%$ aqueous $\mathrm{NH}_{4} \mathrm{~F}$ solution for 15 min under an argon atmosphere. Argon was purged through the $\mathrm{NH}_{4} \mathrm{~F}$ for $30 \mathrm{~min}$ to 
remove $\mathrm{O}_{2}$ before the $\mathrm{Si}(111)$ pieces were immersed. After being etched, the samples were rinsed with water and finally blown dry with a stream of nitrogen. A three-necked flat-bottomed flask connected to a thin capillary as the argon inlet and to a reflux condenser connected to a vacuum pump was charged with individual neat silanol, flushed with argon in order to remove traces of oxygen and moisture. The freshly etched Si (111) substrate was placed in a flask containing the fluorinated silanol under an argon atmosphere. For photochemical modification, silanol compounds were dropped on the freshly etched Si surface and immediately irradiated with a using a $254 \mathrm{~nm}$ lamp (3 $\mathrm{min}$ ). After the reaction had been stopped, the modified surfaces were rinsed and sonicated with $\mathrm{CH}_{2} \mathrm{Cl}_{2}$ for $15 \mathrm{~min}$ to remove any physisorbed silanol compounds. The modified silicon substrates were directly used for surface characterization or stored in the glovebox prior to characterization. The monolayers were extensively analyzed by XPS, IR contact angle measurements and AFM, as described in the Supporting Information.

Hydrolytic Stability Experiments. Hydrolytic stability tests were carried out by placing the modified surfaces in rubber stopper glass vials. Four different aqueous environments were prepared containing deionized (DI) water, neutral PBS ( $\mathrm{pH} 7.4)$, an acidic $(\mathrm{HCl})$ solution at $\mathrm{pH} 3$, and a basic $(\mathrm{NaOH})$ solution at $\mathrm{pH} 11$. The stability for all surfaces was investigated at constant temperature of $25^{\circ} \mathrm{C}$. The vials under study were continuously agitated at $25 \mathrm{rpm}$ using an incubator shaker, benchtop Innova 4080, to mimic mechanical disturbances by flowing solvents; this approach also minimizes the deposition of adventitious carbon on the surface. The stability of the functionalized surfaces under acidic, basic, PBS, and neutral deionized water was monitored directly after preparation, and after 1 day, 7 days, and 30 days of immersion in the described medium in a laboratory environment. In all cases, before measurements, the samples were taken from the medium, rinsed with fresh DI water, sonicated in water, and dichloromethane for $5 \mathrm{~min}$ in each solvent, and finally rinsed with dichloromethane and dried in a flow of dry argon. The samples were returned to new vials filled with freshly prepared solutions for prolonged periods of this stability study. The reported values are the average of five surfaces.

Fouling Experiments. Clean and well-characterized monolayermodified silicon surfaces were used for our fouling studies. For all experiments the concentration of fouling polymer was $10 \mathrm{mg} / \mathrm{mL}$ in DMF. The well-cleaned surface was immersed into the polymer solution for $12 \mathrm{~h}$, and then taken out, washed with DMF for $2 \mathrm{~min}$ in an autoshaker (at $50 \mathrm{rpm}$ ), taken out, rinsed, and this washing step was performed in total three times. Next, the sample was dried in a $80^{\circ} \mathrm{C}$ oven for $2 \mathrm{~h}$. Unfouled monolayers are not affected in any observed manner by this sonication and drying treatment. The extent of absorption (fouling) and the morphology of the adhered polymer on these monolayers were characterized by ellipsometry, XPS and AFM measurements. For each monolayer, the fouling experiments were conducted on three different samples, and on each sample the ellipsometry, XPS and AFM measurements were carried out at least three different places. The reported data in this paper are the average results for all the measurements. Bare silicon was used as reference in this polymer absorption survey.

Computational Procedures. All of the DFT calculations reported herein were carried out using performed using Gaussian 09. ${ }^{70}$ All geometries were fully optimized, and the nature of the stationary points was determined in each case according to the proper number of imaginary frequencies.

\section{ASSOCIATED CONTENT}

\section{S Supporting Information}

The Supporting Information is available free of charge on the ACS Publications website at DOI: 10.1021/jacs.7b01106.

Synthesis, detailed descriptions of characterization techniques (XPS, ellipsometry, static water contact angle measurements, AFM), experimental procedures, supplementary figures $\left({ }^{1} \mathrm{H} \mathrm{NMR},{ }^{13} \mathrm{C} \mathrm{NMR},{ }^{19} \mathrm{~F}\right.$ NMR,
XPS and IR spectra; rate of reaction with various wavelengths) and tables; full ref 70 (PDF)

\section{AUTHOR INFORMATION}

\section{Corresponding Author}

*han.zuilhof@wur.nl

ORCID

Jorge Escorihuela: 0000-0001-6756-0991

Han Zuilhof: 0000-0001-5773-8506

\section{Notes}

The authors declare no competing financial interest.

\section{ACKNOWLEDGMENTS}

We thank Dr. Zhanhua Wang for stimulating discussions and NanoNext (program 3E) for partial funding of this project.

\section{REFERENCES}

(1) Schönherr, H. In Surface Design: Applications in Bioscience and Nanotechnology; Förch, R., Schönherr, H., Jenkins, A. T A., Ed.; WileyVCH: Weinheim, Germany, 2009; Chapter 1, pp 3-28.

(2) Sen, R.; Escorihuela, J.; van Delft, F. L.; Zuilhof, H. Angew. Chem., Int. Ed. 2017, 56, 3299-3303.

(3) Sen, R.; Gahtory, D.; Carvalho, R. R.; Albada, B.; van Delft, F. L.; Zuilhof, H. Angew. Chem., Int. Ed. 2017, 56, 4130-4134.

(4) Peng, F.; Su, Y.; Zhong, Y.; Fan, C.; Lee, S.-T.; He, Y. Acc. Chem. Res. 2014, 47, 612-623.

(5) Garnett, E. C.; Yang, P. Nano Lett. 2010, 10, 1082-1087.

(6) Joo, J.; Liu, X.; Kotamraju, V. R.; Ruoslahti, E.; Nam, Y.; Sailor, M. J. ACS Nano 2015, 9, 6233-6241.

(7) Wang, S.; Liu, K.; Liu, J.; Yu, Z. T. F.; Xu, X.; Zhao, L.; Lee, T.; Lee, E. K.; Reiss, J.; Lee, Y. K.; Chung, L. W. K.; Huang, J.; Rettig, M.; Seligson, D.; Duraiswamy, K. N.; Shen, C. K. F.; Tseng, H. R. Angew. Chem., Int. Ed. 2011, 50, 3084-3088.

(8) Peng, F.; Su, Y. Y.; Zhong, Y. L.; Fan, C. H.; Lee, S. T.; He, Y. Acc. Chem. Res. 2014, 47, 612-623.

(9) Li, F.; Basile, V. M.; Pekarek, R. T.; Rose, M. J. ACS Appl. Mater. Interfaces 2014, 6, 20557-20568.

(10) Garg, K.; Majumder, C.; Nayak, S. K.; Aswal, D. K.; Gupta, S. K.; Chattopadhyay, S. Phys. Chem. Chem. Phys. 2015, 17, 1891-1899.

(11) Garnett, E. C.; Brongersma, M. L.; Cui, Y.; McGehee, M. D. Annu. Rev. Mater. Res. 2011, 41, 269-295.

(12) Peng, W.; Rupich, S. M.; Shafiq, N.; Gartstein, Y. N.; Malko, A. V.; Chabal, Y. J. Chem. Rev. 2015, 115, 12764-12796.

(13) Polman, A.; Knight, M.; Garnett, E. C.; Ehrler, B.; Sinke, W. C. Science 2016, 352, 6283.

(14) Hu, M.; Liu, F.; Buriak, J. M. ACS Appl. Mater. Interfaces 2016, 8, 11091-11099.

(15) Yaffe, O.; Scheres, L.; Puniredd, S. R.; Stein, N.; Biller, A.; Lavan, R. H.; Shpaisman, H.; Zuilhof, H.; Haick, H.; Cahen, D.; Vilan, A. Nano Lett. 2009, 9, 2390-2394.

(16) Xiang, D.; Wang, X.; Jia, C.; Lee, T.; Guo, X. Chem. Rev. 2016, 116, 4318-4440.

(17) Shehada, N.; Cancilla, J. C.; Torrecilla, J. S.; Pariente, E. S.; Brönstrup, G.; Christiansen, S.; Johnson, D. W.; Leja, M.; Davies, M. P. A.; Liran, O.; Peled, N.; Haick, H. ACS Nano 2016, 10, 7047-7057.

(18) Gooding, J. J.; Ciampi, S. Chem. Soc. Rev. 2011, 40, 2704-2718.

(19) Ciampi, S.; Harper, J. B.; Gooding, J. J. Chem. Soc. Rev. 2010, 39, 2158-2183.

(20) Wong, K. T.; Lewis, N. S. Acc. Chem. Res. 2014, 47, 3037-3044.

(21) George, S. M.; Yoon, B.; Dameron, A. A. Acc. Chem. Res. 2009, 42, 498-508.

(22) Yao, S. A.; Ruther, R. E.; Zhang, L. H.; Franking, R. A.; Hamers, R. J.; Berry, J. F. J. Am. Chem. Soc. 2012, 134, 15632-15635.

(23) Haensch, C.; Hoeppener, S.; Schubert, U. S. Chem. Soc. Rev. 2010, 39, 2323-2334. 
(24) Maoz, R.; Burshtain, D.; Cohen, H.; Nelson, P.; Jonathan Berson, J.; Yoffe, A.; Sagiv, J. Angew. Chem., Int. Ed. 2016, 55, 1236612371.

(25) Pujari, S. P.; Scheres, L.; Marcelis, A. T. M.; Zuilhof, H. Angew. Chem., Int. Ed. 2014, 53, 6322-6356.

(26) Miller, J. B.; Schwartz, J.; Bernasek, S. L. J. Am. Chem. Soc. 1993, $115,8239-8247$.

(27) Jung, G.-Y.; Li, Z.; Wu, W.; Chen, Y.; Olynick, D. L.; Wang, S.Y.; Tong, W. M.; Williams, R. S. Langmuir 2005, 21, 1158-1161.

(28) Alekseev, S. A.; Lysenko, V.; Zaitsev, V. N.; Barbier, D. J. Phys. Chem. C 2007, 111, 15217-15222.

(29) Moitra, N.; Ichii, S.; Kamei, T.; Kanamori, K.; Zhu, Y.; Takeda, K.; Nakanishi, K.; Shimada, T. J. Am. Chem. Soc. 2014, 136, 1157011573

(30) Sweetman, M. J.; McInnes, S. J. P.; Vasani, R. B.; Guinan, T.; Blencowe, A.; Voelcker, N. H. Chem. Commun. 2015, 51, 1064010643.

(31) Escorihuela, J.; Pujari, S. P.; Zuilhof, H. Langmuir 2017, 33, $2185-2193$

(32) Vilan, A.; Yaffe, O.; Biller, A.; Salomon, A.; Kahn, A.; Cahen, D. Adv. Mater. 2010, 22, 140-159.

(33) Li, Y.; Calder, S.; Yaffe, O.; Cahen, D.; Haick, H.; Kronik, L.; Zuilhof, H. Langmuir 2012, 28, 9920-9929.

(34) Zhong, Y. L.; Bernasek, S. L. J. Am. Chem. Soc. 2011, 133, 81188121.

(35) Linford, M. R.; Chidsey, C. E. D. J. Am. Chem. Soc. 1993, 115, $12631-12632$

(36) Yang, Z.; Iqbal, M.; Dobbie, A. R.; Veinot, J. G. C. J. Am. Chem. Soc. 2013, 135, 17595-17601.

(37) Linford, M. R.; Fenter, P.; Eisenberger, P. M.; Chidsey, C. E. D. J. Am. Chem. Soc. 1995, 117, 3145-3155.

(38) Sugimura, H.; Mo, S.; Yamashiro, K.; Ichii, T.; Murase, K. J. Phys. Chem. C 2013, 117, 2480-2485.

(39) Wang, X.; Ruther, R. E.; Streifer, J. A.; Hamers, R. J. J. Am. Chem. Soc. 2010, 132, 4048-4049.

(40) Huck, L. A.; Buriak, J. M. Langmuir 2012, 28, 16285-16293.

(41) Buriak, J. M. Chem. Mater. 2014, 26, 763-772.

(42) Dayal, S.; Li, J.; Li, Y.-S.; Wu, H.; Samia, A. C. S.; Kenney, M. E.; Burda, C. Photochem. Photobiol. 2008, 84, 243-249.

(43) Lipke, M. C.; Liberman-Martin, A. L.; Tilley, T. D. Angew. Chem., Int. Ed. 2017, 56, 2260-2294.

(44) Parks, D. J.; Piers, W. E. J. Am. Chem. Soc. 1996, 118, 94409441.

(45) Blackwell, J. M.; Sonmor, E. R.; Scoccitti, T.; Piers, W. E. Org. Lett. 2000, 2, 3921-3923.

(46) Rubin, M.; Schwier, T.; Gevorgyan, V. J. Org. Chem. 2002, 67, $1936-1940$

(47) Hermeke, J.; Mewald, M.; Oestreich, M. J. Am. Chem. Soc. 2013, $135,17537-17546$.

(48) Houghton, A. Y.; Hurmalainen, J.; Mansikkamaki, A.; Piers, W. E.; Tuononen, H. M. Nat. Chem. 2014, 6, 983.

(49) Purkait, T. K.; Iqbal, M.; Wahl, M. H.; Gottschling, K.; Gonzalez, C. M.; Islam, M. A.; Veinot, J. G. C. J. Am. Chem. Soc. 2014, 136, 17914-17917.

(50) Buriak, J. M.; Stewart, M. P.; Geders, T. W.; Allen, M. J.; Choi, H. C.; Smith, J.; Raftery, D.; Canham, L. T. J. Am. Chem. Soc. 1999, 121, 11491-11502.

(51) Wang, Z.; Pujari, S. P.; van Lagen, B.; Smulders, M. M. J.; Zuilhof, H. Adv. Mater. Interfaces 2016, 2, 1500514.

(52) Chinwangso, P.; Jamison, A. C.; Lee, T. R. Acc. Chem. Res. 2011, 44, 511-519.

(53) Pujari, S. P.; Spruijt, E.; Stuart, M. A. C.; van Rijn, C. J. M.; Paulusse, J. M. J.; Zuilhof, H. Langmuir 2012, 28, 17690-17700.

(54) Zhang, F.; Sautter, K.; Larsen, A. M.; Findley, D. A.; Davis, R. C.; Samha, H.; Linford, M. R. Langmuir 2010, 26, 14648-14654.

(55) Nuzzo, R. G.; Dubois, L. H.; Allara, D. L. J. Am. Chem. Soc. 1990, 112, 558-569.

(56) Liu, F.; Hauger, T. C.; Olsen, B. C.; Luber, E. J.; Buriak, J. M. Chem. Mater. 2016, 28, 9158-9168.
(57) De Smet, L. C. P. M.; Pukin, A. V.; Sun, Q.-Y.; Eves, B. J.; Lopinski, G. P.; Visser, G. M.; Zuilhof, H.; Sudhölter, E. J. R. Appl. Surf. Sci. 2005, 252, 24-30.

(58) Sun, Q. Y.; Smet, L. C. P. M. de; van Lagen, B.; Giesbers, M.; Thüne, P. C.; Engelenburg, J.; van Wolf, F. A.; de Zuilhof, H.; Sudhölter, E. J. R. J. Am. Chem. Soc. 2005, 127, 2514-2523.

(59) Vandervoort, P.; Gillisdhamers, I.; Vansant, E. F. J. Chem. Soc., Faraday Trans. 1990, 86, 3751-3755.

(60) Giesbers, M.; Marcelis, A. T. M.; Zuilhof, H. Langmuir 2013, 29, $4782-4788$.

(61) Buriak, J. M.; Sikder, M. D. H. J. Am. Chem. Soc. 2015, 137, 9730-9738.

(62) Albéniz, A. C.; Espinet, P.; López-Fernández, R.; Sen, A. J. Am. Chem. Soc. 2002, 124, 11278-11279.

(63) Khung, Y. L.; Ngalim, S. H.; Meda, L.; Narducci, D. Chem. - Eur. J. 2014, 20, 15151-15158.

(64) Peverati, R.; Truhlar, D. G. J. Phys. Chem. Lett. 2012, 3, 117124.

(65) Kondo, T.; Yamada, R.; Uosaki, K. In Organized Organic Ultrathin Films; Ariga, K., Ed.; Wiley-VCH: Weinheim, Germany, 2013; Ch. 2, pp 7-42.

(66) For a standardized stability protocol, see: Bhairamadgi, N. S.; Pujari, S. P.; Trovela, F. G.; Debrassi, A.; Khamis, A. A.; Alonso, J. M.; Al Zahrani, A. A.; Wennekes, T.; Al-Turaif, H. A.; van Rijn, C.; Alhamed, Y. A.; Zuilhof, H. Langmuir 2014, 30, 5829-5839.

(67) Wang, Z.; Zuilhof, H. J. Mater. Chem. A 2016, 4, 2408-2412.

(68) Banerjee, I.; Pangule, R. C.; Kane, R. S. Adv. Mater. 2011, 23, 690-718.

(69) Wang, Z.; Zuilhof, H. Langmuir 2016, 32, 6571-6581.

(70) Frisch, M. J. et al. Gaussian 09, Revision D.01; Gaussian Inc.: Wallingford, CT, 2009. 